\title{
Interleucinas na encefalopatia hipóxico-isquêmica
}

\author{
Interleukins in hypoxic-ischemic encephalopathy
}

\author{
Maria Esther Jurfest Rivero Ceccon*
}

\begin{abstract}
A asfixia perinatal é um evento grave que pode acometer o feto ou o recém-nascido. Anualmente nascem no mundo 4 milhões de crianças com asfixia perinatal grave, destas, 800.000 morrem em decorrência deste evento, e outras 800.000 evoluem com seqüelas significativas ${ }^{1}$.

No Brasil, segundo Maranhão 2 (1999), a asfixia perinatal, dentro das afecções perinatais, é responsável por $12 \%$ dos óbitos.
\end{abstract}

A encefalopatia hipóxico-isquêmica (EHI) constitui a conseqüência mais grave da asfixia perinatal e ocorre em cerca de $33 \%$ dos recém-nascidos $(\mathrm{RN})$ que a apresentam. É a causa mais comum de convulsão no RN, representando $60 \%$ a $65 \%$ das mesmas, tanto em RN de termo (RNT) como em RN pré-termo (RNPT), sendo importante fator de seqüelas neurológicas a longo prazo $^{3}$.

Novos conhecimentos acerca dos vários mecanismos e eventos fisiopatológicos que ocorrem na EHI, levando à lesão cerebral, são comunicados. Com base nessas evidências, são propostos mecanismos de neuroproteção que devem ser utilizados o mais precocemente possível após a ocorrência do agravo isquêmico, para diminuir a mortalidade e melhorar a qualidade de vida.

Estudos experimentais indicam que a inflamação está envolvida na sua patogênese. A cascata inflamatória deflagrada pela isquemia no sistema nervoso central (SNC) consiste de grande afluxo de leucócitos no local, que incluem neutrófilos, monócitos e macrófagos. Participam também desta cascata, células da microglia, sendo que a ativação destas ocorre mais rapidamente no RN do que em adultos, além de moléculas específicas de adesão intercelular ${ }^{4}$.
* Prof ${ }^{a}$ Livre Docente em Pediatria - Departamento de Pediatria - Faculdade de Medicina da Universidade de São Paulo. Professora médica colaboradora da FMUSP, Assistente Encarregada da Unidade de Cuidados Intensivos Neonatal (UCINE) - Instituto da Criança - HC-FMUSP.
As interleucinas são proteínas que têm uma célula primária de produção, entre as quais linfócitos, monócitos e macrófagos, porém também são produzidas por outras células, como fibroblastos, células da microglia, astrócitos e células do músculo liso. Destas proteínas são conhecidos seus locais cromossômicos, a quantidade de aminoácidos que possuem e inclusive seus receptores celulares. Elas não são estocadas previamente nas suas células produtoras e, portanto, sempre que necessário, são sintetizadas e secretadas em resposta a um estímulo. Uma vez liberadas, têm uma vida-média curta, limitada à atividade biológica que possuem, entre estas atividades, uma das principais é a comunicação entre as células 5 .

Vários autores sugerem que as citocinas orquestram, em parte, a lesão cerebral isquêmica. Minami et al. ${ }^{6}$, em 1992, e Liu et al. ${ }^{7}$, em 1994, induzindo isquemia cerebral em ratos, observaram que a interleucina $1 ß$ (IL-1ß) e o fator de necrose tumoral a (TNF- $\alpha)$, liberadas por monócitos e macrófagos além das células da microglia, estão aumentadas durante a isquemia, e ambas citocinas são capazes de induzir a reação inflamatória no SNC. Outra situação que ilustra a participação destas citocinas é que, utilizando agentes bloqueadores da IL-1ß em modelos animais com isquemia cerebral, observa-se uma diminuição do edema cerebral, com melhora do quadro neurológico.

No entanto, não é claro se estas citocinas têm o mesmo efeito no cérebro neonatal humano após asfixia e se, através delas, se pode fazer prognóstico.

Neste periódico, está publicado estudo de Silveira e Procianoy ${ }^{8}$, no qual avaliaram-se os níveis de interleucina6 e TNF- $\alpha$ no liquor de RNT com EHI, para verificar se estas citocinas estavam aumentadas nestes RN em relação aos controles sadios. Foram incluídos $15 \mathrm{RN}$ com asfixia perinatal, segundo critérios pré-estabelecidos ${ }^{9}$, e $20 \mathrm{RN}$ controles. As amostras para dosagem foram obtidas em média com 17 horas de vida, fato este de muita importância, uma vez que a vida-média das interleucinas não é longa. Os resultados mostraram que os $\mathrm{RN}$ com EHI apresentaram níveis liquóricos de IL-6 e TNF- $\alpha$ significativamente mais 
elevados que os controles, principalmente o TNF- $\alpha$, que é o que deflagra a cascata inflamatória.

Oygur et al. ${ }^{10}$, em 1998, estudando a evolução de 30 RN com EHI, observaram que os níveis mais elevados de IL-1 estiveram associados a uma pior evolução neurológica do que os de TNF- $\alpha$. Ancel et al. ${ }^{11}$, em 1997, estudando 20 RN com EHI, dosaram apenas a IL-6 e observaram que a magnitude da resposta esteve associada com a gravidade da doença e com um pior prognóstico.

Os autores do artigo citado deste Jornal relatam que todos os recém-nascidos que foram a óbito ( $3 \mathrm{RN})$ tinham níveis mais elevados desses mediadores, porém observam que o tamanho da amostra não é suficiente para estabelecer ou não estatisticamente essa possibilidade.

Verificamos, desta maneira, que as interleucinas estão, sem dúvida, envolvidas no processo inflamatório que ocorre ao nível do SNC. Aguardamos que este estudo, o primeiro de nosso conhecimento a estudar as citocinas no liquor de RN asfixiados em nosso meio, seja seguido de outros para, como os autores também referem, abrir caminhos de proteção do SNC contra um evento tão grave como é a asfixia perinatal, quando esta não puder ser evitada.

\section{Referências bibliográficas}

1. Costello AM, Manandhar DS. Perinatal asphyxia in less developed countries [editorial]. Arch Dis Child Fetal Neonatal Ed 1994; 71:F1-3.
2. Maranhão AGK, Joaquim MMC, Siu C. Mortalidade perinatal e neonatal no Brasil. Tema-Radis 1999;17:6-7.

3. Volpe JJ. Neurology of the Newborn. $4^{\mathrm{a}}$ ed. Filadélfia: W.B. Saunders; 2001.p.217-394.

4. Silveira R, Procianoy RS. Niveis plasmáticos de interleucina-1ß e interleucina-6 em recém-nascidos com febre. J Pediatr (Rio J) 1999;75:29-33.

5. Kilpatrick L, Harris MC. Cytokines and the inflammatory response. In: Polin RA, Fox WW, Fletcher J. Fetal and Neonatal Physiology. 2a ed. Filadélfia: W.B. Saunders; 1998.p.1967-79.

6. Minami M, Kuraishi Y, Yabuuchi K, Yamazaki A, Satoh M. Induction of interleukin-1 beta mRNA in rat brain after transient forebrain ischemia. J Neurochem 1992;58:390-2.

7. Liu T, Clark RK, McDonnell PC, Young PR, White RF, Barone FC, et al. Tumor necrosis factor-alpha expression in ischemic neurons. Stroke 1994;25:1481-8.

8. Procianoy RS, Silveira RC. Síndrome hipóxico-isquêmica. J Pediatr (Rio J) 2001;77 Supl 1:63-70.

9. Silveira RC, Procianoy RS. Níveis de interleucina-6 e fator de necrose tumoral-alfa no liquor de recém-nascidos a termo com encefalopatia hipóxico-isquêmica. J Pediatr (Rio J) 2003;74: 297-302.

10. Oygur N, Sonmez O, Saka O, Yegin O. Predictive value of plasma and cerebrospinal fluid tumour necrosis factor- $\alpha$ and interleukin- $1 \beta$ concentrations on outcome of full term infants with hypoxic-ischaemic encephalopathy. Arch Dis Child Fetal Neonatal Ed 1998;79:F190-3.

11. Martin-Ancel A, Garcia-Alix A, Pascual-Salcedo D, Cabanas F, Valcarce M, Quero J. Interleukin-6 in the cerebrospinal fluid after perinatal asphyxia is related to early and late neurological manifestation. Pediatrics 1997;100:789-94. 